\title{
Differentiation between Bernard-Soulier syndrome and immune thrombocytopenia by immunostaining of peripheral blood
}

\author{
L O POULSEN, P JOHANSEN, * M K JENSEN, L FREUND Department of Internal Medicine \\ and Haematology and ${ }^{*}$ Department of Pathology, Aalborg Hospital, Aalborg, Denmark
}

SUMMARY Peripheral blood smears from seven patients with Bernard-Soulier syndrome were examined by an immunocytochemical staining procedure using a monoclonal antibody specific for platelet glycoprotein Ib. No platelet staining was observed except for very slight staining of the large sized platelets from one of the patients. Application of the assay to blood smears from 12 patients with immune trombocytopenia showed that their peripheral platelets stained normally, so the assay can be used to differentiate between immune thrombocytopenia and Bernard-Soulier syndrome and to confirm a diagnosis of the syndrome.

Bernard-Soulier Syndrome is a congenital platelet disorder characterised by prolonged bleeding time, mild to severe thrombocytopenia, large platelets on a peripheral blood smear, normal aggregation response to adenosine diphosphate, epinephrine, and collagen, but no aggregation response to ristocetin even in the presence of human or bovine von Willebrand factor.' In patients with the syndrome a platelet membrane defect has been shown, ${ }^{2}$ which comprises the absence of $^{3-6}$ or severe decrease in ${ }^{3-57}$ the concentration of platelet membrane glycoprotein Ib (GPIb). Different electrophoretic techniques ${ }^{2-5}$ or enzyme linked immunosorbent assays (ELISAs) ${ }^{67}$ have been used to show this defect, but these methods require preparation of platelet rich plasma which may be difficult to obtain from patients with Bernard Soulier syndrome because of giant platelets, ${ }^{1}$ and in infants and children because of the small volumes of blood available. A much simpler procedure is application of an immunoenzymatic assay to a peripheral blood smear. This report describes our experience with the latter technique using a monoclonal antibody specific for GPIb and the alkaline phosphatase-antialkaline phosphatase (APAAP) procedure. ${ }^{8}$

\section{Material and methods}

Seven patients between 8 and 71 years old (mean 39 years) with Bernard Soulier syndrome ${ }^{1}$ were examined. The patients came from four families. Eleven patients aged between 12 and 73 years (mean 49

Accepted for publication 11 July 1989 years) with idiopathic thrombocytopenic purpura (thrombocytopenia, normal bone marrow morphology with normal or increased numbers of megakaryocytes, and no evidence of other types of immune thrombocytopenia) and a 50 year old thrombocytopenic patient with systemic lupus eryth- 8 ematosus were also examinated. This patient and one of the patients with idiopathic thrombocytopenia were treated with prednisone at the time of investigation.? None of the patients received chemotherapy at the time of examination. Twenty healthy subjects aged between 9 and 60 years old (mean 28 years) acted as controls.

Platelet GPIb was detected by the APAAP procedure $^{8}$ using a commercially available monoclonal antibody (Dakopatts, Copenhagen, Denmark) specific for GPIb as the primary antibody. Blood was drawn into routine K-EDTA anticoagulant and conventional peripheral blood smears were made. After fixation in acetone for 90 seconds the smears were incubated for 30 minutes with the GPIb specific monoclonal antibody diluted $1 / 100$. Incubation for 10 minutes with a rabbit anti-mouse immunoglobulin (Dakopatts) at a dilution of 1/25 was performed, followed by 10 minutes' incubation with the APAAP complex (Dakopatts) diluted 1/50. The two latter steps were repeated for 30 minutes each to enhance the final staining reaction. Alkaline phosphatase activity was detected with naphthol AS-MX phosphate $(5 \mathrm{mg})$ in $0.2 \mathrm{ml}$ dimethylformamide. This solution was diluted with $0.1 \mathrm{~mol} / \mathrm{l} \mathrm{TRIS}$ buffer, $\mathrm{pH} 8 \cdot 2$, to a final volume of $10 \mathrm{ml}$. To block endogenous alkaline phosphatase activity $1 \mathrm{~mol} / 1$ levamisol was added, together with Fast-Red TR salt $(10 \mathrm{mg})$. The slides were counter- 
stained with haematoxylin and embedded in paraffin wax for light microscopical examination. Each staining procedure was accompanied by staining a peripheral blood smear from a control. Negative controls were performed by omitting the primary antibody step.

\section{Results}

Platelets from six of the patients with Bernard Soulier syndrome were not stained with the monoclonal antibody specific for platelet GPIb. In one such patient the normal sized platelets were unstained; the large sized platelets were very slightly stained. Platelets from all the patients with immune thrombocytopenia were clearly stained and so were platelets from healthy controls. Only the platelets were GPIb positive. Minor day to day variation in the staining intensity of samples from normal controls were observed.

\section{Discussion}

The results suggest that the applied immunocytochemical staining procedure can be used to show up deficiencies of GPIb and hence to confirm the diagnosis of Bernard Soulier syndrome. GPIb staining showed two different subpopulations in one patient. This phenomenon has previously been noted in juvenile myelodysplastic syndrome ${ }^{910}$ using the more sensitive flow cytometric technique. Our patient was a 52 year old woman with a 12 year history of Bernard Soulier syndrome; her bone marrow aspirate showed no evidence of myelodysplastic syndrome.

Investigation of patients with immune thrombocytopenia was included because, like Bernard Soulier syndrome, ITP is a benign disease, with a low platelet count and prolonged bleeding time. Plateletassociated antibodies of GPIb specificity have been detected in up to $28 \%$ of patients with ITP. ${ }^{11}$ The presence of this antibody does not seem to influence the reactivity of the immunoenzymatic method as no differences could be shown between patients with ITP and normal controls. Differentiation between ITP and Bernard Soulier syndrome is important because the former disease can be treated with immunosuppressive drugs. ${ }^{12}$ The immunoenzymatic method is therefore a valuable addition in the diagnosis of Bernard Soulier syndrome, and furthermore, it differentiates between ITP and Bernard Soulier syndrome.

\section{References}

1 George JN, Nurden AT, Phillips DR. Molecular defects in interactions of platelets with the wessel wall. $N$ Engl $J$ Med 1984;311:1084-98.

2 Nurden AT, Caen JP. Specific roles for platelet surface glycoproteins in platelet function. Nature 1975;255:720-2.

3 Berndt MC, Gregory C, Chong BH, Zola H, Castaldi PA. Additional glycoprotein defects in Bernard-Soulier's syndrome: confirmation of genetic basis by parental analyses. Blood 1983;62:800-7.

4 Clementson KJ, McGregor JL, James E, Dechavanne M, Lüscher EF. Characterization of the platelet membrane glycoprotein abnormalities in Bernard-Soulier syndrome and comparison with normal surface-labeling techniques and high-resolution two-dimensional gel electrophoresis. J Clin Invest 1982;70: 304-11.

5 Nurden AT, Didry D, Rosa J. Molecular defects of platelets in Bernard-Soulier syndrome. Blood cells 1983;9:333-58.

6 Ingerslev J, Stenbjerg S, Taaning E. A case of Bernard-Soulier syndrome: study of platelet glycoprotein Ib in a kindred. Eur $J$ Haematol 1987;39:182-4.

7 Poulsen LO, Taaning E. Variation in platelet glycoprotein I in Bernard-Soulier syndrome. Haemostasis. (In Press).

8 Cordell JL, Falini B, Erber WD, et al. Immunoenzymatic labeling of monoclonal antibodies using immune complexes of alkaline phosphatase and monoclonal anti-alkaline phosphatase (APAAP complexes). J Histochem Cytochem 1984;32:219-29.

9 Michelson AD. Flow cytometric analyses of platelet surface glycoproteins: phenotypically distinct subpopulations of platelets in children with chronic myeloid leukemia. $J$ Lab Clin Med 1987;110:346-54.

10 Berndt MC, Kabral A, Grimsley P, Watson N, Robertson TI, Bradstock KF. An acquired Bernard-Soulier-like platelet defect associated with juvenile myelodysplastic syndrome. $B r J$ Haematol 1988;68:97-101.

11 McMillan R, Tani P, Millard F, Berchtold P, Renshaw L, Woods VL. Platelet-associated and plasma anti-glycoprotein autoantibodies in chronic ITP. Blood 1987;70:1040-5.

12 Jacobs $P$, Wood L, Dent DM. Results of treatment in immune thrombocytopenia, $Q J$ Med 1986;58:153-65.

Requests for reprints to: Dr L O Poulsen, Department of Internal Medicine and Haematology, Aalborg Hospital, PO Box 365, DK-9100 Aalborg, Denmark. 